\title{
논문 3
}

\section{분류층 가스화기 특징 및 공정모사 분석}

유정석*, 김유석, 백민수**

\section{Characteristics and Modeling Analysis of Entrained Flow Gasifiers}

\author{
Jeongseok Yoo*, Youseok Kim and Minsu Paek**
}

Abstract The gasification process has developed to convert coal into the more useful energy and material since decades. Despite the numberous design of ones, entrained flow gasifier of the major companies has had an advantage on the market. Because it has a merit of full-scale and high performance plant. In this paper, the gasification technologies of GE energy, Phillips, Siemens and Shell have been reviewed to compare their characteristics and a high performance gasification process was suggested. And the simulation model of gasifiers using Aspen Plus offered the quantitative comparison data for difference designs. The simulation results revealed the poor performance of the slurry feed than dry design. The corresponding cold gas efficiency of $77 \%$ is much lower than the $80.3 \%$ for the dry feed cases. The exergy analysis of the difference syngas quenching system showed that chemical quenching is superior to another. The results of analysis recommend the two stage gasifier with dry multi-feeder as the energy effective design.

Key words Entrained flow gasifier(분류층 가스화기), Slurry feed(슬러리 주입), Dry feed(건식 주입), Syngas Quenching(합성가스 냉각)

(접수일 2013. 5. 16, 수정일 2013. 9. 9, 게재확정일 2013. 9. 23)

* 두산 중공업 주식회사 (Doosan Heavy Industries \& Construction)

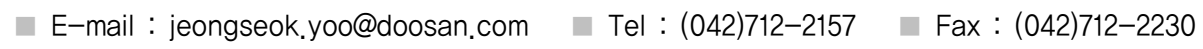

** 두산 중공업 주식회사 (Doosan Heavy Industries \& Construction)

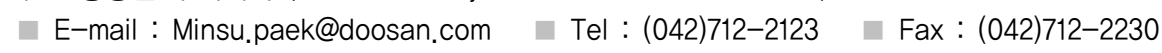

\section{Nomenclature}

\author{
$C G E$ : cold gas efficiency, \% \\ $E \quad:$ total exergy, $\mathrm{kcal} / \mathrm{hr}$ \\ $E_{T}^{Q}$ : thermal exergy of heat available at $T$, \\ $\mathrm{kcal} / \mathrm{hr}$ \\ $E^{W}$ : working power, kcal/hr \\ $h \quad$ : enthalpy, $\mathrm{kcal} / \mathrm{kg}$ \\ $H H V$ : high heating value, $\mathrm{kcal} / \mathrm{kg}$
}

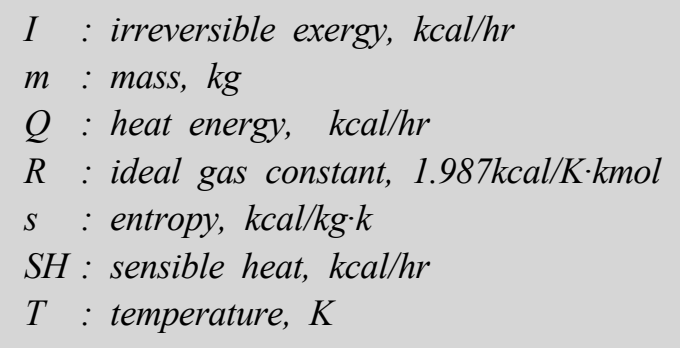


$W$ : working energy, $\mathrm{kcal} / \mathrm{hr}$

$x$ : mole fraction

\section{Greek}

$\varepsilon_{p h} \quad$ : specific physical exergy, $\mathrm{kcal} / \mathrm{hr}$

$\mathcal{E}_{c h} \quad$ : specific chemical exergy of ideal steam, $\mathrm{kcal} / \mathrm{hr}$

$\mathcal{E}_{\text {ch, gas }}$ : specific chemical exergy of gas, $\mathrm{kcal} / \mathrm{hr}$

$\varepsilon_{o i} \quad$ : standard molar chemical exergy of $i$ component in an ideal mixture, $\mathrm{kcal} / \mathrm{hr}$

$\mathcal{E}_{\text {ch, coal }}$ : specific chemical exergy of coal, $\mathrm{kcal} / \mathrm{hr}$

$\eta \quad:$ efficiency, $\%$

\section{subscript}

$\begin{array}{ll}\text { bfw } & : \text { boiler feed water } \\ e & : \text { energy } \\ i & : \text { component } \\ \text { st } & : \text { steam } \\ \text { syn } & : \text { syngas } \\ 0 & : \text { standard } \\ \text { IN } & : \text { input stream to control volume } \\ \text { OUT } & : \text { outgoing stream from control volume }\end{array}$

\section{1. 서 론}

석탄, 바이오매스, 잔류오일 등을 보다 유용한 물질인 합 성가스 연료, 화학물질로 전환하기 위해 수십 년 전부터 가스 화 방법이 개발되어 현장에 적용되어 왔다. 현재까지 개발된 가스화기술은 방식에 따라, 고정층, 이동층, 분류층으로 구 분 할 수 있다. 분류층 가스화기술은 다른 가스화기술과 비교 하여 사용할 수 있는 석탄이 제한적이지만, 고효율, 대형화의 장점을 가지고 있어 Shell, GE Energy, Siemens 등 세계적 인 주요기업 주도하에 세계시장의 $50 \%$ 이상을 점유하고 있 다. ${ }^{(1)}$ 국내도 최근 Shell과 Phillips 공정이 도입되어 태안과 광양에 건설 중에 있으며, 하동과 삼척에 추가 가스화 플랜트 건설을 고려하고 있다.
본 연구에서는 분류층 가스화 기술을 대표하는 GE energy, Phillips, Shell, Siemens의 석탄 가스화 기술 특성을 비교하 고, 공정모델 분석을 통하여 보다 우수한 가스화 방식을 제안 하였다. 가스화 공정별 기술 분석은 문헌 등을 기반으로 정리 하였으며, 공정모사를 통한 성능 비교를 위하여 Aspen Plus 가 사용되었다. 공정모사 결과에 대한 신뢰성 확보를 위하여, 플랜트 운전 자료를 기반으로 검증된 공정별 모델이 사용되 었다. 개발된 공정별 모델을 이용한 에너지 및 엑서지 분석 결과를 통하여 공정별 특성을 정량적으로 비교하였다.

\section{2. 본 론}

\section{1 공정별 특성 분석}

가스화 공정은 일반적으로 석탄을 분쇄하여 고압으로 이송 하는 시스템, 가스화기, 슬래그 제거설비 그리고 합성가스 냉 각시스템과 집진설비를 포함한다. 현재까지 개발된 다양한 형태의 가스화 공정은 석탄 주입방식, 가스화기 형상, 버너 위치, 생성된 합성가스에 대한 냉각 및 열 회수방식 등에 의 하여 특징지어 진다.

\subsection{1 석탄 주입방식}

고압 가스화기에 미분탄 주입은 석탄을 물과 혼합(석탄/(물 +석탄) 무게비, 50 70\%)하여 주입하는 슬러리 주입(Slurry feed)방식과 기존 화력발전소와 같이 석탄을 수분함량 $2 \%$ 수 준까지 건조시켜 주입하는 건식 주입(Dry feed)방식으로 구 분된다. ${ }^{(2)}$

슬러리 주입은 GE energy와 Phillips에서 선택한 방식으 로 펌프를 이용하여 슬러리 석탄을 $100 \mathrm{bar}$ 이상까지 가압할 수 있기 때문에 건식 주입과 비교하여 보다 간단한 설비로 고 압운전이 가능하다. 반면에 석탄에 포함된 염소성분과 고압 슬러리 이송 때문에 펌프, 이송배관, 버너노즐 등 특정 부위 에 부식, 마모가 발생되어, 최근에는 재질을 개선하고 있다. 저급 석탄의 경우에는 석탄에 존재하는 고 수분 때문에 이송 에 적합한 슬러리 제작이 어려운 것으로 알려져 있다. ${ }^{(3)}$

건식 주입은 Shell과 Siemens에서 선택한 방식으로 석탄 을 건조하여 고압 질소로 이송 시키는 방식이다. 건식 주입방 


\section{논문 3}

식의 문제는 설비 구성과 운전 과정이 복잡하다는 것과 수분 에 의한 석탄 부착이 발생하지 않도록 충분히 건조해야 한다 는 것이다. 이와 같은 문제를 해결하기 위해 석탄 저장고가 약 $80 \mathrm{~m}$ 상부에서 하부까지 3 단에 걸쳐 설치되고, 가압, 이 송, 압력조정 등, 9 단계의 복잡한 운전 과정을 통해 주입되 기 때문에 장치와 설치비가 상대적으로 고가이다. ${ }^{(2)}$

\subsection{2 가스화 공정}

1) $\mathrm{GE}$ energy 가스화기

$\mathrm{GE}$ energy 가스화기는 하향류식 단일버너로 가스화기 벽 면은 내화벽돌로 구성되어 있다. 가스화 과정에서 생성된 합 성가스는 가스화기 하부에 설치된 복사 전열관을 통과하면서 $700^{\circ} \mathrm{C}$ 까지 냉각된다. Fig. 1에서 보는 것과 같이 GE energy 가스화기는 설비자체가 단순하여 경제적인 설치가 가능하지 만 에너지 효율이 상대적으로 낮은 것으로 보고되고 있다. ${ }^{(4)}$

\section{2) Phillips(P-66) 가스화기}

Phillips 가스화기는 상향류식 2단 가스화기로 GE energy 와 동일하게 내화벽돌이 설치되어, 경제적인 제작, 설치가 가

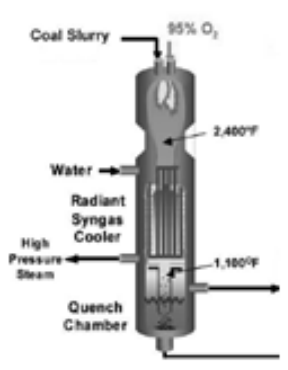

(a) GE energy

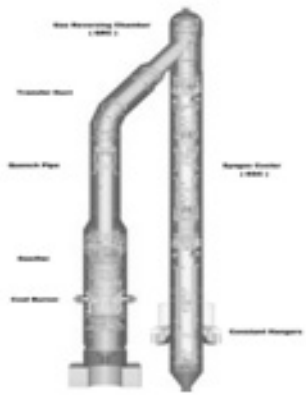

(c) Shell (SCGP)

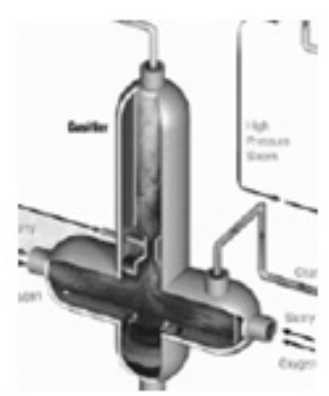

(b) Phillips (P-66)

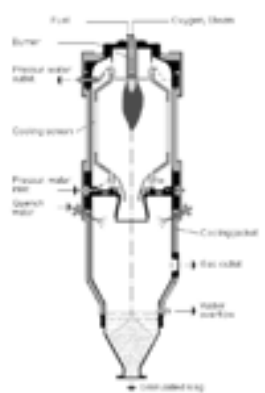

(d) Siemens (SFG-500)
Fig. 1 Schematics of coal gasifier
능한 것으로 알려져 있지만 가스화기의 구조적인 문제로 이 용률이 상대적으로 낮은 것이 단점이다. 그러나 2 단 연료주 입 방식을 사용하고 있어, 가스화에 필요한 산소량을 줄이고 합성가스 중에 $\mathrm{CH}_{4}$ 농도를 높게 유지할 수 있다. ${ }^{(5)}$

3) Shell(SCGP) 가스화기

Shell 가스화기는 4 개의 버너를 가지고 있는 상향류 가스 화기이다. 가스화기 내부의 열을 회수하기 위해 내화벽돌 대 신에 수냉벽(Membrane wall)을 설치하고 합성가스 냉각기 를 가스화기와 일체형으로 구성한 것이 특징이다. ${ }^{(3)}$ 가스화 기 중에 상대적으로 설비가 복잡하여 설치비가 고 가이나, 에 너지 효율이 높은 것으로 알려져 있다. 또한, 가스화기를 구 성하는 수냉벽은 운전조건을 준수할 경우, 내화벽돌과는 다 르게 교체하지 않고 20 년 이상의 사용할 수 있다. ${ }^{(2)}$

\section{4) Siemens $(\mathrm{SFG}-500)$}

Siemens 가스화기는 하향류식 단일 버너 방식의 가스화기 이지만 건식 석탄 주입방식을 사용하고 있으며, 가스화기 내 벽은 Shell 가스화기와 같은 수냉벽으로 구성되어 있다. 생성 된 합성가스는 가스화기 하부에 설치된 수분 분사 장치에 의 해 쉽게 냉각되기 때문에 설비의 간편성, 운전조건 가변성에 장점을 가지고 있다. ${ }^{(2)}$

\subsection{3 합성가스 냉각방식}

합성가스 냉각시스템은 가스화 과정에서 생성된 용융 슬래 그와 비산재를 제거하면서 열을 유용하게 회수할 수 있도록 고안된 장치이다. 합성가스와 함께 이동하는 비산재는 가스 화기 벽면과 전열관 등에 Fouling 현상을 일으킨다. 특히 열 교환기에 Fouling을 방지하기 위하여 석탄재의 용융 특성을 고려하여 설계하고 있다. ${ }^{(2)}$

Fig. 2는 대표적인 합성가스 냉각기술을 나타낸 것이다. ${ }^{(6)}$ 열회수 냉각방식(HRSC; Heat Recove ry Syngas Cooler Quenching)을 사용하고 있는 GE energy는 가스화기 하부에 RSC(Radiant Syngas Cooler)와 이후 CSC(Convective Syngas Cooler)를 설치하여 발생된 열을 스팀으로 회수할 수 있도록 설계하였다.

화학적 냉각방식(Chemical Quenching)은 석탄과 산소를 주입하는 1단 가스화기 상부에 석탄만을 주입하는 2 단 가스 화 반응 영역을 만들어 탄소가 일산화탄소로 전환되는 흡열 


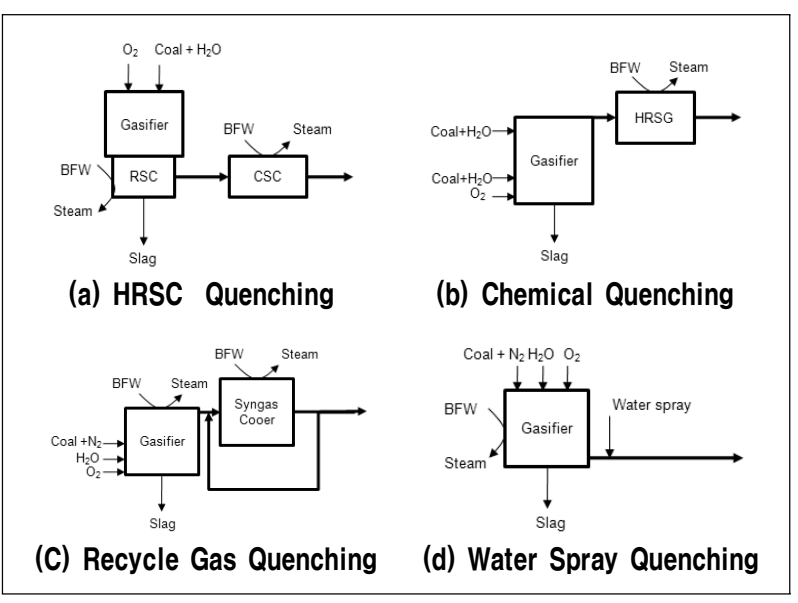

Fig. 2 Overall diagram of syngas quenching

반응을 유도하여 냉각하는 방식이다. Phillips에서는 화학적 냉각방식을 채택하여 $1400^{\circ} \mathrm{C}$ 의 합성가스를 $1000^{\circ} \mathrm{C}$ 까지 냉 각시킨 후에 열을 스팀으로 회수한다.

가스 재순환 냉각방식(Recycle Gas Quenching )을 선택 하고 있는 Shell에서는 $250^{\circ} \mathrm{C}$ 로 냉각된 합성가스를 가스화 기 출구 단으로 재순환시키는 방법으로 $1400^{\circ} \mathrm{C}$ 의 합성가스 온도를 $900^{\circ} \mathrm{C}$ 까지 냉각시킨다. 재순환 방식은 합성가스를 재순환하기 위한 압축 에너지 손실을 제외하면 합성가스 현 열을 대부분 스팀으로 회수할 수 있다.

마지막으로 Siemens에서는 $1400^{\circ} \mathrm{C}$ 의 합성가스를 가스화 기 하부에서 수분을 분사하여 $300^{\circ} \mathrm{C}$ 까지 냉각하는 물분사 냉각방식(Water Spray Quenching)을 채택하고 있다. 냉각 을 위해 분산된 수분은 대부분 기화되어 합성가스에 포함되 기 때문에 합성가스의 현열은 높으나, 스팀 회수율은 매우 낮다.

\section{2 공정모사 및 엑서지 계산}

\subsection{1 공정모사 방법}

가스화기 공정모사는 화학공정에서 널리 사용하고 있는 Aspen Plus를 사용하였다. Aspen Plus는 고체연료에 대한 해석기능 때문에 그 동안 석탄 가스화기 뿐만 아니라 바이오 매스 가스화기 공정모사 등 다양한 영역에 활용되고 있다.

1) 석탄 조성

공정모사를 위하여 역청탄 중 발열량이 $6,165 \mathrm{kcal} / \mathrm{kg}(\mathrm{HHV}$
Table 1. Coal composition attributes

\begin{tabular}{c|c|c|c|c|c}
\hline \multicolumn{2}{c|}{ Proximate analysis } & \multicolumn{2}{c|}{ Ultimate analysis } & \multicolumn{2}{c}{ Sulfur analysis } \\
\hline Element & $\mathrm{Wt} \%$ & Element & $\mathrm{Wt}, \%$ & Element & $\mathrm{Wt}, \%$ \\
\hline Moisture & 11.04 & Ash & 16.47 & Pyritic & 0.70 \\
\hline FC & 39.82 & Carbon & 67.63 & Sulfate & 0.00 \\
\hline VM & 32.67 & Hydrogen & 4.39 & Organic & 0.19 \\
\hline ASH & 16.47 & Nitrogen & 1.55 & & \\
\hline & & Chlorine & 0.01 & & \\
\hline & & Sulfur & 0.89 & & \\
\hline & & Oxygen & 9.06 & & \\
\hline
\end{tabular}

기준)에 속하는 호주탄을 대상으로 하였다. 석탄 조성은 아래 Table 1과 같다. 수분 함량 $11.04 \%$ 의 석탄은 건식 주입방식 에서는 $2 \%$ 로 건조되며, 슬러리 주입의 경우는 석탄과 물의 비율이 무게비로 $67: 33$ 으로 혼합되어 가스화기에 주입된다.

\section{2) 가스화기 공정모사}

석탄 주입량은 Table 1 의 석탄조성을 고려하여 정상 상태 에서 2,500ton/day로 선정하였다. 가스화기 열손실은 문헌 값 $1.5 \%$ 를 균일하게 반영하였다. ${ }^{(7)}$ 석탄에 포함된 Tar는 모 델에 반영하지 않고 Char에는 탄소와 Ash만을 포함하는 것 으로 가정하였다.

Aspen Plus로 모사된 전 공정의 일반적인 혼합 물질의 물 리적 특성계산은 물과 탄화수소 혼합 공정에 보다 적합한 $\mathrm{SRKKB}$ (Kabadi-Danner에 의해 보정된 RK-Soave식)식을 이용하였다. ${ }^{\left({ }^{8}\right)}$ 부가적으로 석탄과 석탄재에 대한 엔탈피와 밀도 계산을 위하여 HCOALGEN과 DCOALGT 모델이 사용 되었다. ${ }^{(9)}$ 가스화 모델은 Yield 반응기와 Gibbs 모델로 구성 하고 Table 2에 정리된 화학 반응식을 고려하여 가스화기 개

Table 2. Implemented reactions in Gibbs reactor

\begin{tabular}{l|c|c}
\multicolumn{1}{c|}{ Reaction } & $\Delta \mathrm{H}_{\mathrm{R}, 0}(\mathrm{~kJ} / \mathrm{mol})$ & \\
\hline $\mathrm{C}+\mathrm{O}_{2} \rightarrow \mathrm{CO}_{2}$ & -406.3 & $\mathrm{R} 1$ \\
\hline $\mathrm{C}+\mathrm{CO}_{2} \leftrightarrow 2 \mathrm{CO}$ & +159.6 & $\mathrm{R} 2$ \\
\hline $\mathrm{CO}+3 \mathrm{H}_{2} \leftrightarrow \mathrm{CH}_{4}+\mathrm{H}_{2} \mathrm{O}$ & -206.2 & $\mathrm{R} 3$ \\
\hline $\mathrm{CO}+\mathrm{H}_{2} \mathrm{O} \leftrightarrow \mathrm{H}_{2}+\mathrm{CO}_{2}$ & -41.1 & $\mathrm{R} 4$ \\
\hline $\mathrm{H}_{2}+\mathrm{S} \leftrightarrow \mathrm{H}_{2} \mathrm{~S}$ & -20.5 & $\mathrm{R} 5$ \\
\hline $\mathrm{CO}+\mathrm{S} \leftrightarrow \mathrm{COS}$ & -27.9 & $\mathrm{R} 6$ \\
\hline $\mathrm{Cl}_{2}+\mathrm{H}_{2} \leftrightarrow 2 \mathrm{HCl}$ & -184.6 & $\mathrm{R} 7$ \\
\hline $\mathrm{N}_{2}+3 \mathrm{H}_{2} \leftrightarrow 2 \mathrm{NH} \mathrm{H}_{3}$ & -91.9 & $\mathrm{R} 8$ \\
\hline $\mathrm{CO}+\mathrm{NH}_{3} \leftrightarrow \mathrm{HCN}+\mathrm{H}_{2} \mathrm{O}$ & +49.8 & $\mathrm{R} 9$ \\
\hline
\end{tabular}




\section{논문 3}

별 특성을 반영하였다.

Table 3은 공정모사에 사용된 일반 설계 경계조건이며, Table 4는 공정모사에 사용한 가스화기의 설계 경계조건을 나타낸 것이다. 설계 경계조건은 그 동안 발표되었던 가스화 기 공정별 운전 및 설계 자료를 참고하여 정리한 것이 다. ${ }^{(3,4,10)}$ 성능을 결정하는 가스화기 운전 온도는 석탄에 포함 된 탄소 몰(mole)량 대비 주입되는 산소량과 수분량에 의해 계산된 수치이며, 개별 가스화기의 통상 운전 범위에 포함되 도록 하였다.

가스화기 공정모델은 J. Yoo(2009)에 의하여 개발된 석탄

\section{Table 3. General boundary condition}

\begin{tabular}{c|c|c}
\hline Parameter & Value & Comment \\
\hline Environmental Temperature & $25^{\circ} \mathrm{C}$ & \\
\hline Environmental Pressure & $1.013 \mathrm{bar}$ & \\
\hline Dry atmosphere & $\mathrm{N}_{2} 78.1 \%, \mathrm{O}_{2} 21.0 \%, \mathrm{Ar} 0.9 \%$ vol \\
\hline $\mathrm{O}_{2}$ Purity & $95 \%$ & $\mathrm{Ar} \%, \mathrm{~N}_{2} 2 \%$ vol \\
\hline $\mathrm{O}_{2}$ Temperature & $240^{\circ} \mathrm{C}$ & \\
\hline Moderate Steam & $45 \mathrm{bar} / 257^{\circ} \mathrm{C}$ & Saturated ST \\
\hline Quench water & $37 \mathrm{bar} / 150^{\circ} \mathrm{C}$ & Preheating \\
\hline Middle Pressure Steam & $53 \mathrm{bar} / 270^{\circ} \mathrm{C}$ & $\mathrm{BFW} 63 \mathrm{bar} / 220^{\circ} \mathrm{C}$ \\
\hline High Pressure Steam & $140 \mathrm{bar} / 338^{\circ} \mathrm{C}$ & $\mathrm{BFW} 150 \mathrm{bar} / 220^{\circ} \mathrm{C}$ \\
\hline
\end{tabular}

Table 4. Unified boundary condition for gasifier modeling

\begin{tabular}{|c|c|c|}
\hline Parameter & GE Energy ${ }^{(4)}$ & Phillips-P66 ${ }^{(10)}$ \\
\hline Coal feeding & Wet & Wet \\
\hline Chamber & Refractory & Refractory \\
\hline Quench & Radiant/HRSC & Chemical Quench \\
\hline Pressure, bar & 38 & 38 \\
\hline Temp. ${ }^{\circ} \mathrm{C}$ & 1380 & $1387 / 1004$ \\
\hline $\mathrm{O}_{2} / \mathrm{C} \mathrm{mol} \%$ & 0.489 & 0.4362 \\
\hline Steam/C, mol\% & - & - \\
\hline $\mathrm{H}_{2} \mathrm{O} /$ coal, wt $\%$ & 0.330 (Transfer) & 0.330 (Transfer) \\
\hline Parameter & Shell-SCGP ${ }^{(10)}$ & Siemens-SFG500 ${ }^{(10)}$ \\
\hline Coal feeding & Dry & Dry \\
\hline Chamber & Membrane wall & Cooling Screen \\
\hline Quench & Gas Recycle & Full Water \\
\hline Pressure, bar & 42 & 35 \\
\hline Temp. ${ }^{\circ} \mathrm{C}$ & 1450 & 1450 \\
\hline $\mathrm{O}_{2} / \mathrm{C} \mathrm{mol} \%$ & 0.453 & 0.453 \\
\hline Steam/C mol\% & 0.095 & 0.095 \\
\hline $\mathrm{N}_{2} /$ coal, wt $\%$ & 0.125 (Transfer) & 0.125 (Transfer) \\
\hline
\end{tabular}

가스화 공정모델 ${ }^{(11)}$ 을 개선하였다. 모델 개선은 기존의 Gibbs 모델에서 얻어진 화학 평형온도를 보정하여 개별 반응식에 대입하여 계산하는 방법으로 Gibbs 에너지 최소화 계산 결과 를 미세하게 조정하기 위해 수행된다. ${ }^{(12)}$ 여기서, 보정 온도 는 실증 운전 자료를 기반으로 결정되기 때문에 가스화기 특 성이 반영된 경험적인 수치로 가스화기 종류에 따라 고유 값 을 갖는다. 본 연구에서는 Table 2에 제시된 R2, R4, R9 반 응에 대하여 $0 \sim 200^{\circ} \mathrm{C}$ 범위에서 가스화 반응 온도를 보정하 여 사용하였다.

개발된 가스화기 모델에 대한 신뢰성 검증은 실증 자료와 함께 문헌값 ${ }^{(3,10)}$ 비교를 통해 실시되었다. 검증 결과, 주요 성분에 대해서는 $\pm 3 \%$ 이내 오차범위였으며, 미세 성분에 대 해서는 $\pm 5 \%$ 이상을 넘지 않았다.

공정모사에서 효율 계산은 석탄이 합성가스로 전환되는 전 환효율(CGE: Cold Gas Efficiency)과 열 회수효율로 나타낼 수 있다. 가스화기 에너지 효율은 식 (1)과 같이 합성가스 발 열량과 스팀 회수 에너지의 합을 석탄의 발열량, 냉각을 위해 투입되는 일 에너지, 유입되는 현열의 합으로 나눈 값으로 정 의하였다. 여기서, $\mathrm{W}$ 는 합성가스 냉각을 위하여 투입된 일 에너지이며, $\mathrm{SH}$ 는 가스화기에 유입되는 현열이다.

$$
\eta_{e}=\frac{\left(m_{\text {syn }} \cdot H H V_{s y n}\right)+\left(m_{s t} \cdot\left(h_{s t}-h_{b f w}\right)\right)}{m_{c o a l} \cdot H H V_{c o a l}+W+S H}
$$

\subsection{2 엑서지 계산 방법}

가스화 과정에 대한 엑서지 계산은 위치와 운동 엑서지를 무시하고 아래 식과 같이 화학, 물리 엑서지의 합으로 나타낼 수 있다.

$$
E=N\left(\varepsilon_{p h}+\varepsilon_{c h}\right)
$$

$$
\begin{aligned}
& \text { 여기서, } \\
& \varepsilon_{p h}=\left(h-h_{0}\right)-T_{0}\left(s-s_{0}\right) \\
& \varepsilon_{c h, g a s}=\sum_{i} x_{i} \varepsilon_{o i}+R T \sum_{i} x_{i} \ln x_{i}
\end{aligned}
$$

엑서지 계산에 필요한 물질에 대한 몰분율, 유량, 엔탈피 와 엔트로피는 Aspen Plus 모사 결과로부터 계산하였으며, Table 3에 제시된 외부 조건을 기준 엑서지로 하였다. 특히, 
석탄에 대한 화학 엑서지 $\varepsilon_{\mathrm{oi}}$ 값은 J. Szargut(2004)에 의해 제시된 방법에 따라 $\beta$ 보정계수를 계산하고 아래 식 (3)과 같 이 발열량의 비로 계산하였다. ${ }^{(13)}$

$$
\varepsilon_{c h, c o l}=H H V_{\text {fuel }} \beta
$$

계에 전달된 일은 엑서지 값과 동일하게 계산하였으며, 열 에너지는 아래 식 (4)와 같이 Carnot Factor를 이용하여 계 산하였다.

$$
E_{T}^{Q}=Q\left(1-T_{0} / T\right)
$$

결론적으로 계에 유입되고 배출되는 엑서지 수지는 아래 식 (5)와 같이 표기되며, 여기서 I는 회수할 수 없는 에너지 손실에 해당된다.

$$
\sum_{I N} E_{c h}+\sum_{I N} E_{T_{I N}}^{Q}=\sum_{O U T} E_{c h}+\sum_{O U T} E_{T_{O U T}}^{Q}+\sum_{O U T} E^{W}+I
$$

따라서 엑서지 효율 계산은 식 (6)과 같이 계산할 수 있다.

$$
\eta_{E}=1-\frac{I}{\sum_{I N} E_{c h}+\sum_{I N} E_{T_{I N}}^{Q}}
$$

\section{3. 결과 및 토의}

\section{1 공정모사 결과}

동일한 역청탄을 대상으로 4 종류 가스화기에 대한 공정모 사 결과를 Table 5 에 정리하였다. 에너지 효율은 Shell 가스 화기가 $92.99 \%$ 로 가장 높은 결과를 보였으며, 이는 NETL (2009) 등의 보고서의 예측 결과와 동일한 경향을 나타내고 있다. ${ }^{(3,10)}$ 이와 같은 성능 차이는 앞서 언급한 석탄 주입방법, 합성가스 냉각방식, 가스화기 구조 등의 영향에 의해 나타난 종합적인 결과이다.

석탄 주입방식에 따른 합성가스 전환효율의 차이는 $\mathrm{GE}$ energy와 Shell 가스화기의 결과에서 찾을 수 있다. Shell 가 스화기와 비교하여 슬러리로 주입되는 GE energy 가스화기
는 증가된 3.4 배의 수분으로 인해 가스화 과정에서 보다 많은 열을 흡수해야 하며, 이를 위해 산소 소비량이 약 $8 \%$ 증가 하였다. 결과적으로 증가된 산소는 이산화탄소 발생을 증가 시켜 합성가스 전환효율을 감소시킨다.

상기 결과인 석탄 주입방식에 따른 효과만을 보기위해 Fig. 3에 수분량 변화와 산소 주입량 변화에 따른 합성가스 전환율을 그래프로 나타내었다. 그래프 내부 실선은 합성가 스 전환효율이며, 점선은 온도 선으로 분류층 가스화기의 운 전 온도 영역을 표기한 것이다. 온도 선은 오른쪽으로 진행할 수록 온도가 상승한다. GE energy 가스화기의 슬러리 주입 조건을 표시한 점 $\mathrm{A} 1$ 이 건식 주입조건으로 바뀌게 되면서 점 $\mathrm{A} 2$ 로 내려오게 된다. 결과적으로 합성가스 전환효율은 $3.3 \%$ (77\%에서 $80.3 \%$ 상승)상승하고 산소 소모량은 슬러리 주입 조건과 비교하여 $7.2 \%(0.83$ 에서 0.77 감소) 감소하였다.

가스화기 운전조건에 영향을 받는 합성가스 조성은 수분량

\begin{tabular}{|c|c|c|c|c|}
\hline Parameter & GE & Phillips & Shell & Siemens \\
\hline $\begin{array}{c}\text { Syn gas } \\
\text { Mass Flow, kg/hr }\end{array}$ & 192,070 & 189,341 & 190,700 & 192,411 \\
\hline HHV/LHV (MW) & $532 / 502$ & $577 / 541$ & $567 / 540$ & $564 / 541$ \\
\hline SteamYield (MW) & 108.26 & 71.48 & 96.14 & 2.69 \\
\hline $\begin{array}{c}\text { Carbon Conversi- } \\
\text { on rate }(\%)\end{array}$ & 95.00 & 96.30 & 98.70 & 98.30 \\
\hline $\begin{array}{c}\text { Cold Gas } \\
\text { Efficiency (\%) }\end{array}$ & 75.95 & 82.28 & 80.88 & 80.43 \\
\hline $\begin{array}{c}\text { Energy } \\
\text { Efficiency (\%) }\end{array}$ & 91.07 & 92.18 & 92.99 & 79.51 \\
\hline $\begin{array}{c}\text { Component } \\
\text { Volume rate }(\%)\end{array}$ & \multicolumn{4}{|c|}{ Syngas composition after wet scrubber } \\
\hline $\mathrm{H}_{2} \mathrm{O}$ & 8.845 & 8.822 & 7.925 & 9.203 \\
\hline$A R$ & 0.925 & 0.807 & 0.857 & 0.847 \\
\hline $\mathrm{CO}_{2}$ & 12.679 & 10.400 & 3.853 & 3.805 \\
\hline $\mathrm{O}_{2}$ & 0.000 & 0.000 & 0.000 & 0.000 \\
\hline $\mathrm{N}_{2}$ & 1.108 & 1.029 & 6.207 & 5.933 \\
\hline $\mathrm{CH}_{4}$ & 0.007 & 0.861 & 0.011 & 0.008 \\
\hline $\mathrm{CO}$ & 47.294 & 47.557 & 56.224 & 55.566 \\
\hline $\cos$ & 0.030 & 0.019 & 0.028 & 0.027 \\
\hline $\mathrm{H}_{2}$ & 28.838 & 30.222 & 24.619 & 24.338 \\
\hline $\mathrm{H}_{2} \mathrm{~S}$ & 0.269 & 0.274 & 0.272 & 0.269 \\
\hline $\mathrm{NH}_{3}$ & 0.004 & 0.007 & 0.004 & 0.004 \\
\hline
\end{tabular}
증가에 따라 증가되는 수소 농도와 함께 저온 가스영역에서 증가되는 $\mathrm{CH}_{4}$ 발생량에 의해 합성가스 발열량이 증가한다.

\section{Table 5. Results of gasifier modeling}




\section{누눈 3}

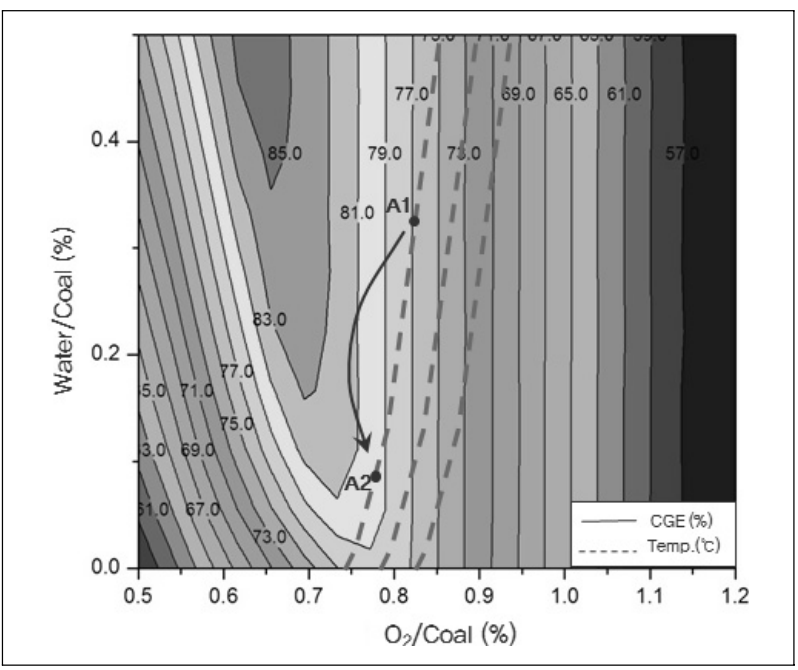

Fig. 3 Performance map of gasifier depend on operation condition

Table 6. Comparison of heat recovery efficiency

\begin{tabular}{c|c|c|c|c}
\hline Items & GE & Phillips & Shell & Siemens \\
\hline Exergy efficiency (\%) & 48.83 & 39.92 & 39.12 & 1.20 \\
\hline
\end{tabular}

Phillips 가스화기는 1 단에서 $1387^{\circ} \mathrm{C}$ 로 운전되다가 2단 영역 에서 주입되는 석탄 연료로 인해 부다반응(흡열반응, R2)이 주로 일어나 $1004^{\circ} \mathrm{C}$ 로 낮아지면서 $\mathrm{H}_{2}$ 와 $\mathrm{CH}_{4}$ 발생을 증가시 킨다. 이와 같은 이유로 Phillips 가스화기는 GE energy 가 스화기와 같이 탄소 전환율이 95 96\% 수준으로 낮음에도 불 구하고 합성가스 전환효율이 $82.28 \%$ 로 높게 계산되었다.

가스화기 전체 에너지 효율에 $10 \%$ 정도 기여하는 열 회수 효율은 엑서지 분석을 통하여 가스화기 종류별 분석결과를 표준화하였다. 가스화 과정에서 생성된 물리 엑서지가 유용 한 스팀으로 회수되는 엑서지 효율을 식 (6)을 이용하여 계산 하면 Table 6 과 같다. GE energy 가스화기의 열회수 냉각방 식이 가장 높은 엑서지 효율을 보였으며, Shell 가스화기의 가스 재순환 냉각방식의 경우에는 유용한 스팀을 상대적으로 많이 회수하고 있으나, 효율적인 방법이라고 볼 수 없었다. 즉 열교환 면적을 증가시키는 것이 가스 재순환을 통한 열교 환 방식보다 성능이 우수하였다. 물분사 냉각방식을 사용하 고 있는 Siemens 가스화기의 경우는 일부 가스화기 벽면에 설치된 수냉벽에서 회수되는 스팀을 제외하고 대부분의 열을 현열로 배출하고 있기 때문에 엑서지 효율이 $1.2 \%$ 로 매우 낮 게 계산되었다.
Table 7. Exergy comparison of gasification

\begin{tabular}{c|c|c|c|c}
\hline Items & GE & Phillips & Shell & Siemens \\
\hline Input Exergy (MW) & 615.4 & 633.7 & 661.5 & 655.2 \\
\hline Output Exergy & & & & \\
\hline Chemical Exergy (MW) & 509.8 & 549.3 & 539.8 & 555.6 \\
\hline Physical exergy (MW) & 29.4 & 28.5 & 26.4 & 57.9 \\
\hline Steam exergy (MW) & 51.6 & 35.6 & 47.3 & 1.2 \\
\hline Irreversible exergy (MW) & 24.6 & 20.3 & 48.0 & 40.1 \\
\hline Exergy loss (MW) & 54.0 & 48.8 & 74.4 & 98.4 \\
\hline Exergy efficiency (\%) & 91.2 & 92.3 & 88.8 & 85.0 \\
\hline
\end{tabular}

합성가스 냉각방식 중에 화학적 냉각방식을 채택하고 있는 Phillips 가스화기를 다른 가스화기 들과 비교하기 위하여 상 기의 유용한 스팀 회수 엑서지 계산과는 다르게 화학 엑서지 를 엑서지 효율 계산과정에 포함하여 냉각 방식에 따른 엑서 지 효율을 계산하였다. 합성가스의 화학 엑서지는 냉각, 혼합 등의 과정에서 서로 반응하지 않는 것으로 가정하였으며, 엑 서지 계산은 식 (2)에 의하여, 엑서지 수지는 식 (5)에 의해 계산하여 Table 7에 정리하였다. 결과를 살펴보면 Phillips 가스화기의 엑서지 효율이 $92.3 \%$ 로 가장 우수하였다. 이는 2 단 가스화 영역에서 생성된 합성가스의 화학 엑서지가 증가 했기 때문이다. 여기서 유입 엑서지는 합성가스의 화학 엑서 지, 물리 엑서지 그리고 추가 유입되는 일 엑서지의 총합이 며, 배출되는 엑서지는 엑서지 별로 분류하여 표시하였다. 엑 서지 손실은 회수할 수 없는 엑서지와 현열로 배출되는 엑서 지의 합이다.

화학적 냉각방식의 가스화기는 1 단, 2 단 가스화 영역에 주 입되는 석탄주입 비율에 따라서, 합성가스 전환 성능에 영향 을 주기 때문에 이에 대한 비교가 필요하다. 2 단 가스화 영 역의 석탄 주입비는 가스화 형상과 운전 조건에 영향을 받지 만 일반적으로 $0.1 \sim 0.4$ 범위에서 최적화되는 것으로 보고되 고 있다. ${ }^{(14)}$ Phillips 가스화기를 대상으로 1단과 2단 가스화 영역에 주입하는 연료량의 비를 변경하면서 합성가스 전환효 율을 비교한 결과는 Fig. 4 와 같다. 모사결과에 의하면 2 단 가스화 영역에 석탄 주입비 $0.35,1$ 단 가스화 영역 주입비 0.65 에서 $83.82 \%$ 의 가장 높은 합성가스 전환효율을 보였다. 그러나 2단 가스화 영역에 주입되는 석탄 비율이 0.35 이상 증가할 경우에는 오히려 성능이 감소하였다. 


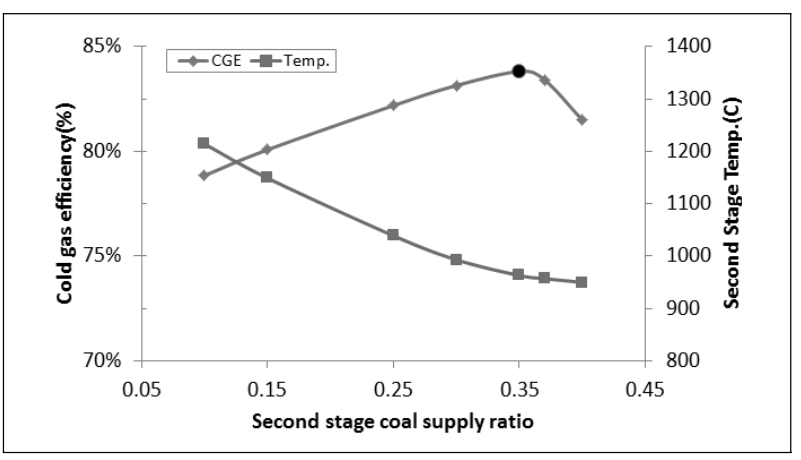

Fig. 4 Comparison CGE and syngas temperature depend on second stage coal supply rate

\section{2 결과 토의}

지금까지 설명된 내용과 모사결과를 종합하면 다음과 같 다. 에너지효율 측면에서 Shell 가스화기가 높은 것으로 예측 되었으나, Siemens 가스화기를 제외하면 1 2\% 내외의 낮은 차이를 보였다. 그러나 엑서지 분석결과는 Phillips 가스화기 가 보다 월등하게 우수한 결과를 얻었다. 이와 같은 차이는 가스화기에 유입되는 현열만을 계산하는 에너지 계산 방법과 다르게 산소, 스팀이 가지고 있는 화학, 물리 엑서지가 유입 엑서지에 반영되었기 때문이다.

석탄 주입은 슬러리 주입방식과 비교하여 건식 주입방식이 합 성가스 전화효율과 다양한 석탄 활용 측면에서 모두 유리하였다. 합성가스 냉각방식은 유효 스팀의 회수율 측면에서는 전열 면적을 넓히는 열회수 냉각방식이 유리하였다. 그러나 특정 열교환 영역에서의 석탄 비산재의 부착 문제와 생성된 합성 가스 전환효율을 고려한다면 화학적 냉각방식이 가장 우수한 것으로 판단되었다.

화학적 냉각방식의 가스화기는 Fig. 4 의 결과처럼, 1 단과 2 단 가스화 영역에 주입되는 석탄비율에 따라 전환효율이 $5 \%$ 이 상 차이를 보이기 때문에 적절한 비율을 찾는 것이 중요하다.

그밖에 분류층 가스화기 성능에 영향을 줄 수 있는 버너 위 치 및 형상 등에 대해서는 본 연구에서 고려되지 않았다.

\section{4. 결 론}

본 연구에서는 분류층 가스화기를 대표하는 GE Energy,
Phillips, Shell, Siemens 가스화기를 대상으로 가스화기별 특성을 분석하고, Aspen Plus를 이용하여 공정모사를 수행 하였다. 공정모사 결과에 대한 신뢰성을 확보하기 위하여, 발 표된 운전 결과와 공정모사의 예측결과 비교를 통해 $\pm 5 \%$ 이 상의 오차가 발생하지 않도록 모델을 구성하였다.

공정 분석결과, 슬러리 주입방식은 수분 주입량이 많기 때 문에 합성가스 전환효율이 $77 \%$ 수준으로 건식 주입방식 $80.3 \%$ 와 비교하여 낮은 효율을 보였다. 그러므로 건식 석탄 주입방식을 선택한다면 슬러리 주입 방식과 비교하여 $3.3 \%$ 성능개선, $7.2 \%$ 산소량 감소효과를 기대할 수 있다.

합성가스 온도를 필요한 온도로 낮추고 유효스팀으로 열을 회수하는 가장 효과적인 방법은 $48.83 \%$ 의 엑서지 효율로 계 산된 열회수 냉각방식이지만 비산재 및 슬래그 점성으로 열 회수 장치의 Fouling 등을 고려한다면 화학적 냉각방식이 가 장 효율적인 냉각방식인 것으로 분석되었다. 화학적 냉각방 식의 가스화기 운전을 위하여 2 단 가스화 영역의 석탄 주입 비는 석탄 조성과 운전조건에 따라 다를 수 있으나, Phillips 가스화기의 경우 성능측면에서 1 단과 2 단의 석탄 분배비율 0.65: 0.35 범위에서 최적화되었다.

상용화된 가스화 공정별 분석 결과, 건식 석탄주입 설비와 2 단 가스화로 구성된 화학적 냉각방식이 우수한 가스화 공정 인 것으로 판단되었다. 그러나 보다 현실적인 접근을 위해서 는 추가적으로 가스화기 및 합성가스 냉각기에 대한 구조적 인 연구가 필요할 것으로 판단된다.

\section{후 기}

본 연구는 2013년 산업통산부 재원으로 한국에너지 기술평 가원(KETEP)의 지원을 받아 수행한 한국형 $300 \mathrm{MW}$ 급 IGCC 실증플랜트 기술개발사업 연구과제입니다(2011951010001A).

\section{References}

[1] Global IGCC Power Market and Strategies, 2007-2030, Emerging Energy Research, Chapter 6, pp. 7-8, 2007.

[2] Coal Fleet User Design Basis Specification for Coal Based 
Integration Gasification Combined Cycle (IGCC) Power Plant, Electric Power Research Institute, Chapter 8, 2011.

[3] C. Kunze and H. Spliethoff, "Modeling, comparison and operation experiences of entrained flow gasifier", Energy Conversion and Management Vol. 52, pp. 2135-2141, 2011.

[4] R. Domentichini et, al. "Integration Gasification Combined Cycle(IGCC) Design Considerations for Carbon Dioxide $\left(\mathrm{CO}_{2}\right)$ capture interim report”, Electric Power Research Institute, Vol. 6, pp. 1-45, 2009.

[5] L. Chen, R. Nolan and S. Avadhany, "Thermodynamic Analysis of Coal to Synthetic Natural Gas Process", Massachusetts Institute of Technology, 2009.

[6] M. Grabner and B. Meyer, "Modeling-based Evaluation of Gasification Processes for High ash Coals", $5^{\text {th }}$ International Freiberg Conference IGCC \& XtL Technologies, 2012.

[7] C. Higman and M. Van der Burgt, Gasification, 2nd ed. Elsevier Gulf Professional Publishing, 2008.

[8] V.N. Kabadi and R.P. Danner, "A modified Soave-RedlichKwong equations of State for water-hydrocarbon phase equilibria”, Ind. Eng. Chem Process Des. Dev. Vol. 24,

\section{유 정 석}

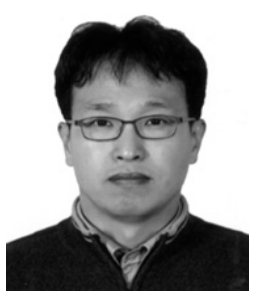

1993 년 경희대학교 환경학과 이학사 1995년 경희대학교 환경학과 대기오염제어 이학석사

현재 두산중공업 기술연구원 책임연구원

(E-mail : jeongseok.yoo@doosan.com) pp. 573-541, 1985.

[9] J. E. Preciado, J. J. Ortiz-Martinez, J. C. Gonzalez-Rivera, R. Sierra-Ramirez and G. Gordillo, "Simulation of Synthesis Gas Production from Steam Oxygen Gasification of Colombian Coal Using Aspen Plus”, Energies Vol. 5, pp. 4924- 4940, 2012.

[10] M. C. Woods et al. "Cost and National Gas to Electricity Final Report”, DOE/NETL, 2007.

[11] J. Yoo, M. Paek and Y. Kim, "Development of Process Model to Prediction Performance of Coal IGCC Plant", KSME Conference, 2009

[12] H. Lee, S. Choi and M. Paek, "Interpretation of coal gasification modeling in commercial process analysis simulation codes", Journal of Mechanical Science and Technology, Vol. 24(7), pp. 1515-1521, 2010.

[13] J. Szargut, Exeregy method Technical and Ecological Applications, wit press, pp. 19-56, 2005.

[14] A. Silaen and T. Wang, "Investigation of the Coal Gasification Process Under Various Operating Conditions Inside a Two-Stage Entrained Flow Gasifier", Journal of Thermal Science and Engineering Applications, Vol. 4 021006, pp. 1-11, 2012.

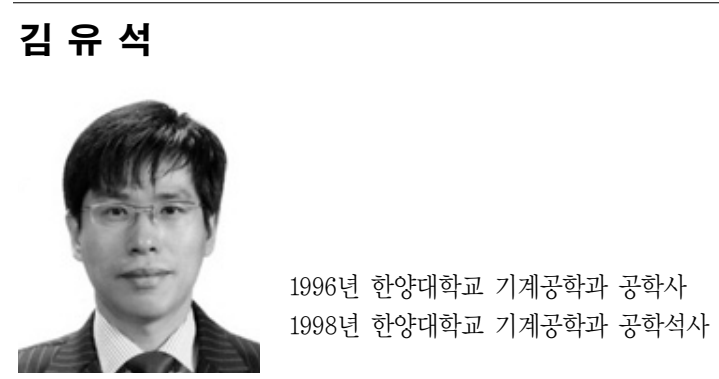

현재 두산중공업 기술연구원 책임연구원

(E-mail : you-seok.kim@doosan.com)

\section{백 민 수}

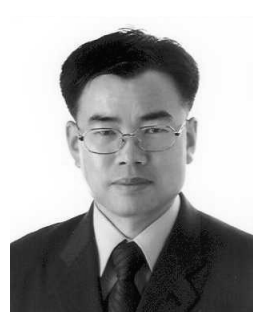

1986 부산대학교 기계설계공학과 공학사

1989 부산대학교 기계공학과 공학석사

1995 부산대학교 기계공학과 공학박사
현재 두산중공업(주) 기술연구원 수석연구원

(E-mail : minsu.paek@doosan.com) 